\title{
On the use of COMSOL Multiphysics for seawater intrusion in fractured coastal aquifers
}

\author{
B. Mozafari ${ }^{1}$, M. Fahs ${ }^{2}$, B. Ataie-Ashtiani ${ }^{1,3}$, C. T. Simmons ${ }^{3}$, Rafic Younes ${ }^{4}$ \\ ${ }^{1}$ Department of Civil Engineering, Sharif University of Technology, Tehran, Iran \\ ${ }^{2}$ Laboratoire d'Hydrologie et Geochemie de Strasbourg, University of Strasbourg/ \\ EOST/ENGEES, CNRS, Strasbourg, France \\ ${ }^{3}$ National Centre for Groundwater Research \& Training and College of Science \& \\ Engineering, Flinders University, Adelaide, Australia \\ ${ }^{4}$ Faculty of Engineering, Lebanese University, Rafic Harriri Campus, Hadath, Beirut, \\ Lebanon
}

\begin{abstract}
COMSOL Multiphysics is a comprehensive simulation software environment for a wide range of applications. COMSOL has an interactive interface that facilitates the modeling procedure and allows an easy coupling of different physical processes. The Subsurface Flow module extends the COMSOL modeling environment to applications related to fluid flow in saturated and variably saturated porous media. COMSOL is increasingly used in the investigation of geophysical, hydrogeological and environmental phenomena. The main goal of this work is to explore the ability of COMSOL for simulating seawater intrusion (SWI) in fractured coastal aquifers. Numerical modeling of such a problem is of high interest as fractured/karstic coastal aquifers are widespread and processes of SWI in the presence of fractures remains poorly understood. We set up a COSMOL model for the popular Henry problem. The accuracy of COMSOL is highlighted by comparison against the semianalytical solutions for simple homogeneous aquifers. For fractured aquifers, the performance of COSMOL is evaluated by comparison against an in-house finite element model based on the discrete fracture model and against the results of existing works. Given its versatility and flexibility, COMSOL shows promise as a tool for SWI in coastal aquifers.
\end{abstract}

\section{INTRODUCTION}

Numerical models are considered as irreplaceable tools for the simulation of SWI in coastal aquifers [Werner et al., 2013]. Although several numerical codes are available, modeling SWI remains a vibrant research discipline of high interest of the scientific community. Modeling of SWI reveals several multifaceted challenges that are not common in other hydrogeological applications. These challenges are related to the physical processes that require coupling between variable-density flow and transport equations, the specific type of seaward boundary conditions and the variable velocity field induced by the salinity buoyant effects. The modeling challenges become more complex in fractured coastal aquifers where fractures require specific numerical techniques to be accurately handled. The objective of this work is to explore the ability of COMSOL Multiphysics [COMSOL, 2012] for simulating SWI in fractured coastal aquifers. COMSOL is a comprehensive simulation software environment for a wide range of applications. It is a user-friendly tool that facilitates all the modeling steps (preprocessing, meshing, solving and postprocessing). The primary advantage of COMSOL is that it easily allows coupling several physical processes together to include all the necessary factors for a complete model. COMSOL includes a module called "Subsurface Flow" devoted to the simulation of fluids flow in saturated and variably saturated porous media. This module allows for considering fractures via the 
discrete fracture network (DFN) model [Sebben et al., 2015] which assumes that fracture size is small compared to a representative elementary volume. With DFN, fractures are represented in (n-1) dimensional element embedded in an n-dimensional computational domain [Ramasomanana et al., 2018]. The use of COMSOL in applications related to hydrogeology is increasingly frequent. To the best of our knowledge, this software has been never applied to SWI in fractured aquifers. Hence, the capacity of COMSOL to deal with the challenges related to SWI in fractured coastal aquifers is worthy of investigation. In this context, we set up a COSMOL model for the popular Henry problem [Henry, 1964; Sebben et al., 2015; Fahs et al., 2016]. The accuracy of COMSOL is highlighted by comparison against the semianalytical solutions for simple homogeneous domains [Fahs et al., 2016]. For fractured domains, the performance of COSMOL is evaluated by comparison against an in-house finite element model based on the discrete fracture model (DFM) [Younes et al., 2009; Ramasomanana et al., 2018] and against the results of the Hydro-GeoSphere code published in Sebben et al. [2015].

\section{PROBLEM DESCRIPTION, GOVERINING EQUATIONS AND SOFTWARE}

To evaluate the performance of COMSOL for modeling SWI we used the Henry problem [Henry, 1964] which is an abstraction of SWI in a vertical cross-section of a confined coastal aquifer perpendicular to the shoreline. In this aquifer, an inland freshwater flow is in natural equilibrium with the seawater intruded from the seaside due to its higher density (Figure 1). Henry problem is widely used as a surrogate for the understanding of SWI processes in coastal aquifers. Because of the existence of semianalytical solutions, Henry problem has been accepted as one of the primary benchmark for the assessment of SWI numerical codes. A new semianalytical solution has been developed in Fahs et al. [2016] for velocity dependent dispersion. This solution is used here to test the performance of COMSOL in the case of simple porous media. The standard Henry problem considers homogenous porous media. Recently Sebben et al. [2015] presented a new configuration by considering fractured coastal aquifer. Several fractures configurations have been suggested in Sebben et al. [2015]. Two among these configurations are used in this work. The first one deals with one horizontal fracture as in Figure 2.a while the second one consists of a network of fractures as in Figure 2.b.

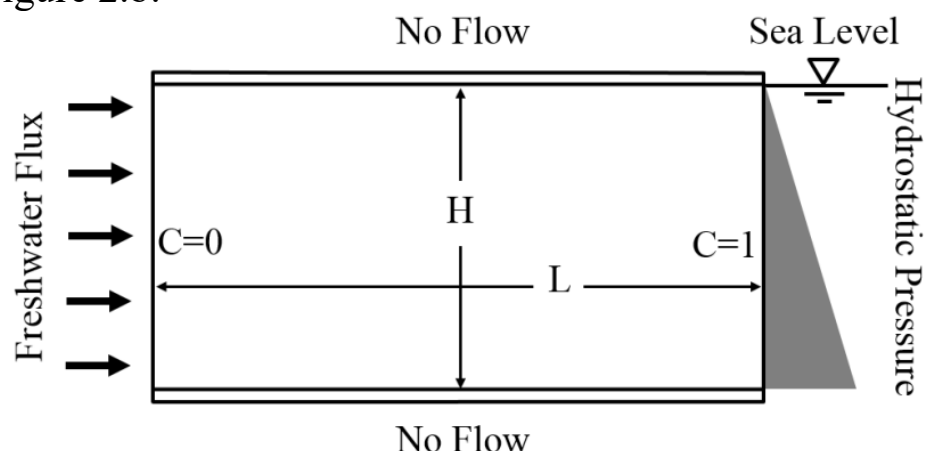

Figure 1. Henry problem domain and boundary conditions. 
a)

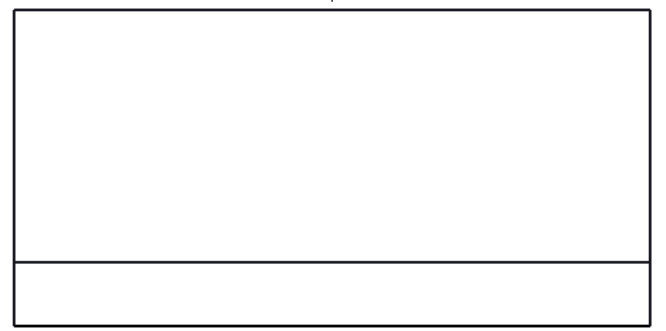

b)

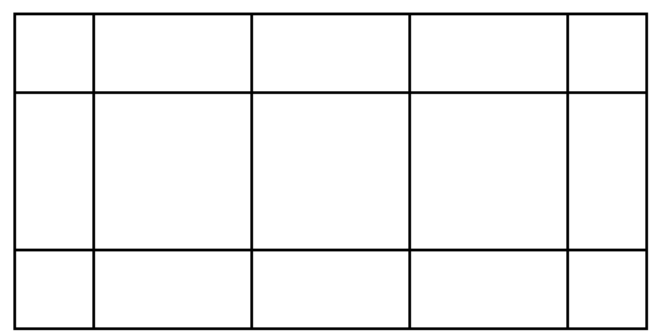

Figure 2. Two cases of fracture networks, a) A horizontal fracture, and b) HorizontalVertical fractures network.

In COMSOL, the Darcy's Law interface has been used for study water flow in the coastal aquifer. According to Darcy's Law, three factors affecting velocity field are the pressure gradient, the fluid viscosity, and the porous medium structure. Therefore, the net flux across a face of the porous surface is

$$
u=-K\left(\nabla h+\frac{\rho-\rho_{0}}{\rho_{0}} e_{z}\right),
$$

where $u$ is the Darcy velocity $[\mathrm{m} / \mathrm{s}], h$ is hydraulic head $[\mathrm{m}], K$ is hydraulic conductivity tensor $[\mathrm{m} / \mathrm{s}], e_{z}$ is a unit vector in the direction that gravity acts, $\rho$ is fluid density $\left[\mathrm{kg} / \mathrm{m}^{3}\right]$ that depends on concentration $(c)$,

$$
\rho=\rho_{0}\left(1+\beta \frac{c}{c_{s}}\right)
$$

where $c_{s}$ is seawater concentration and $\beta=\left(\rho_{s}-\rho_{0}\right) / \rho_{0}$.

With COMSOL the fractures can be included using the DFN model. With this model the fractures are considered as lines (1D). The flow within the fractures is modeled using the Darcy's law with very high permeability.

In coupled interface with Darcy's law, the Transport of Diluted Species Interface provides a predefined modelling environment in which it is possible to examine the transport of chemical species by diffusion and convection, wherein diffusion follows Fick's law. The interface assumes that all existing species have been diluted. Due to the dilution, the properties of the mixture, such as density and viscosity, can be assumed to be consistent with solvents. The interface implements mass balance equation:

$$
u . \nabla c=\nabla \cdot(D \nabla c),
$$

where $c$ is the concentration of the species $\left[\mathrm{mol} / \mathrm{m}^{3}\right]$, D denotes the hydrodynamic diffusiondispersion tensor $\left(\mathrm{m}^{2} / \mathrm{s}\right)$, $\mathrm{u}$ is the velocity vector $(\mathrm{m} / \mathrm{s})$, which is obtained using Darcy law as a coupled interface in this case. $\mathrm{D}$ is equal to $\left(D_{D}+\varepsilon D_{m} I\right)$, where $\mathrm{D}_{\mathrm{D}}$ and $\mathrm{D}_{\mathrm{m}}$ are, respectively, the mechanical dispersion (tensor) and molecular diffusion (scalar). I is an identity matrix and $\varepsilon$ is the porosity. $\mathrm{D}_{\mathrm{D}}$ is defined as below:

$$
D_{D}^{x x}=\alpha_{L} \frac{u_{x}^{2}}{|u|}+\alpha_{T} \frac{u_{y}^{2}}{|u|}, D_{D}^{y y}=\alpha_{T} \frac{u_{x}^{2}}{|u|}+\alpha_{L} \frac{u_{y}^{2}}{|u|}, D_{D}^{x y}=D_{D}^{y x}=\left(\alpha_{L}-\alpha_{T}\right) \frac{u_{x} u_{y}}{|u|}
$$

\section{RESULTS}

\section{Simple porous media: Comparison against the semi analytical solutions}

We first checked the performance of COMSOL for SWI in simple porous media. To do so we compared COMSOL against the semianalytical solutions presented in Fahs et al. [2016]. We checked the three cases presented in that paper. The parameters considered in the three 
cases are given in table 1 . The main isochlors $(25 \%, 50 \%$ and $75 \%)$ obtained with COMSOL as well as the semianalytical ones are given in Figure 3. This figure shows excellent agreement between COMSOL and the semianalytical solution and highlights the accuracy of COMSOL. The third test case is computationally challenged as the transport processes are dominated by advection. The finer grid level generated by the COMSOL meshing tool is used to obtain a solution matching with the semianalytical solution. For coarser mesh COMSOL can generate unphysical oscillations that lead to convergence problems.

Table 1. Physical parameters used in COMSOL.

\begin{tabular}{|c|c|c|c|c|c|}
\hline Parameter & \multicolumn{5}{|c|}{ Value } \\
\hline & \multicolumn{3}{|c|}{ Simple aquifer } & \multicolumn{2}{|c|}{ Fractured aquifer } \\
\hline Length $(\mathrm{L}, \mathrm{m})$ & \multicolumn{3}{|c|}{3} & \multicolumn{2}{|c|}{2} \\
\hline Height $(\mathrm{H}, \mathrm{m})$ & \multicolumn{3}{|c|}{1} & \multicolumn{2}{|c|}{1} \\
\hline Gravity $\left(\mathrm{g}, \mathrm{m} / \mathrm{s}^{2}\right)$ & \multicolumn{3}{|c|}{9.81} & \multicolumn{2}{|c|}{9.81} \\
\hline Freshwater density $\left(\rho_{\mathrm{f}}, \mathrm{kg} / \mathrm{m}^{3}\right)$ & \multicolumn{3}{|c|}{1000} & \multicolumn{2}{|c|}{1000} \\
\hline Seawater density $\left(\rho_{\mathrm{s}}, \mathrm{kg} / \mathrm{m}^{3}\right)$ & \multicolumn{3}{|c|}{1025} & \multicolumn{2}{|c|}{1025} \\
\hline $\begin{array}{l}\text { Freshwater concentration }\left(\mathrm{c}_{0},\right. \\
\left.\mathrm{mol} / \mathrm{m}^{3}\right)\end{array}$ & \multicolumn{3}{|c|}{0} & \multicolumn{2}{|c|}{0} \\
\hline $\begin{array}{l}\text { Seawater concentration }\left(\mathrm{c}_{\mathrm{s}},\right. \\
\left.\mathrm{mol} / \mathrm{m}^{3}\right)\end{array}$ & \multicolumn{3}{|c|}{1} & \multicolumn{2}{|c|}{1} \\
\hline Porosity $(\varepsilon,-)$ & \multicolumn{3}{|c|}{0.35} & \multicolumn{2}{|c|}{0.2} \\
\hline Viscosity $(\mu, \mathrm{kg} / \mathrm{m} / \mathrm{s})$ & \multicolumn{3}{|c|}{$10^{-3}$} & \multicolumn{2}{|c|}{$10^{-3}$} \\
\hline Permeability $\left(\kappa, \mathrm{m}^{2}\right)$ & \multicolumn{3}{|c|}{$1.0204 \times 10^{-9}$} & \multicolumn{2}{|c|}{ - } \\
\hline Freshwater inflow velocity & \multicolumn{3}{|c|}{$6.6 \times 10^{-5}$} & \multicolumn{2}{|c|}{$6.6 \times 10^{-6}$} \\
\hline & Test case 1 & Test case 2 & Test case 3 & Case A & Case B \\
\hline $\begin{array}{l}\text { Molecular diffusion } \\
\text { coefficient }\left(\mathrm{D}_{\mathrm{m}}, \mathrm{m}^{2} / \mathrm{s}\right)\end{array}$ & $18.86 \times 10^{-6}$ & $9.43 \times 10^{-8}$ & $9.43 \times 10^{-8}$ & $10^{-9}$ & $10^{-9}$ \\
\hline $\begin{array}{l}\text { Matrix Longitudinal } \\
\text { dispersivity }\left(\alpha_{\mathrm{L}}, \mathrm{m}\right)\end{array}$ & 0 & 0.1 & 0.001 & 0.1 & 0.1 \\
\hline $\begin{array}{l}\text { Matrix Transverse } \\
\text { dispersivity }\left(\alpha_{\mathrm{T}}, \mathrm{m}\right)\end{array}$ & 0 & 0.01 & 0.0001 & 0.01 & 0.01 \\
\hline $\begin{array}{l}\text { Horizontal hydraulic } \\
\text { conductivity }\left(\mathrm{K}_{\mathrm{x}}, \mathrm{m} / \mathrm{s}\right)\end{array}$ & - & - & - & $2.5 \times 10^{-4}$ & $2.5 \times 10^{-4}$ \\
\hline $\begin{array}{l}\text { Vertical hydraulic } \\
\text { conductivity }\left(\mathrm{K}_{\mathrm{y}}, \mathrm{m} / \mathrm{s}\right)\end{array}$ & - & - & - & $2.5 \times 10^{-4}$ & $2.5 \times 10^{-4}$ \\
\hline $\begin{array}{l}\text { Fracture Longitudinal } \\
\text { dispersivity }\left(\alpha_{\mathrm{LF}}, \mathrm{m}\right)\end{array}$ & - & - & - & 0.1 & 0.1 \\
\hline $\begin{array}{l}\text { Fracture conductivity }\left(\mathrm{K}_{\mathrm{f}} \text {, }\right. \\
\mathrm{m} / \mathrm{s})\end{array}$ & - & - & - & 0.772 & 0.122 \\
\hline Fracture aperture $(2 b, m)$ & - & - & - & $9.71 \times 10^{-4}$ & $3.85 \times 10^{-4}$ \\
\hline
\end{tabular}

\section{Fractured porous media}

The parameters used for the fractured configurations are given in table 1. Steady state simulations have been performed. When regular triangular meshes are used COMSOL encounters convergence difficulties. To avoid this problem we use the option boundary later mesh. When creating a boundary layer mesh, COMSOL creates an initial mesh in which the boundary layer elements are inserted. Example of boundary layer mesh is given in Figure 4 . COMSOL results have been compared against an advanced in-house numerical model based on the discrete fracture model in which the fractures are considered as 2D domain [Younes et al., 2009; Ramasomanana et al., 2018]. The results (not presented for sake of brevity) show excellent agreement between COMSOL and the in-house code which confirms the ability of DFN model to simulate SWI in fractured coastal aquifers. The COMSOL resulting isochlors 
for both configurations are given in Figure 5. This figure shows similar results as the ones obtained by Sebben et al. [2015] using the Hydro-GeoSphere code (see Figure 4 in their paper). It should be noted that for the comparison with Sebben et al. [2015], variable concentration boundary conditions are imposed at the seaside. Despite that this boundary condition is not common; it has been implemented directly in COMSOL via the interactive interface.

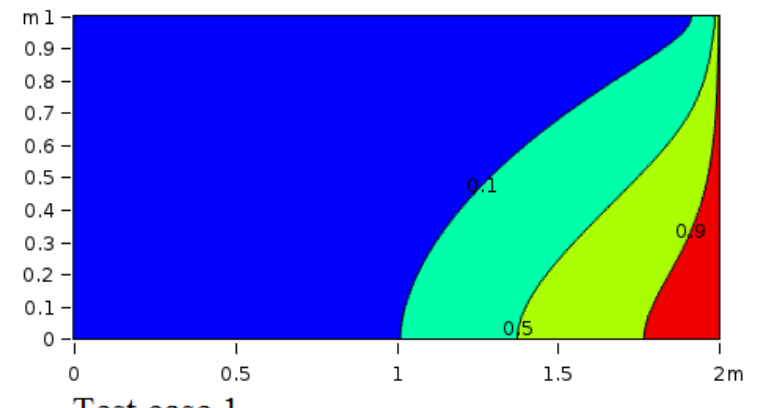

Test case 1

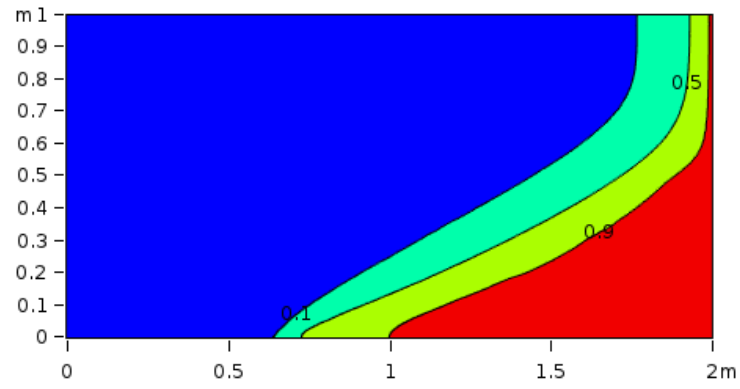

Test case 2

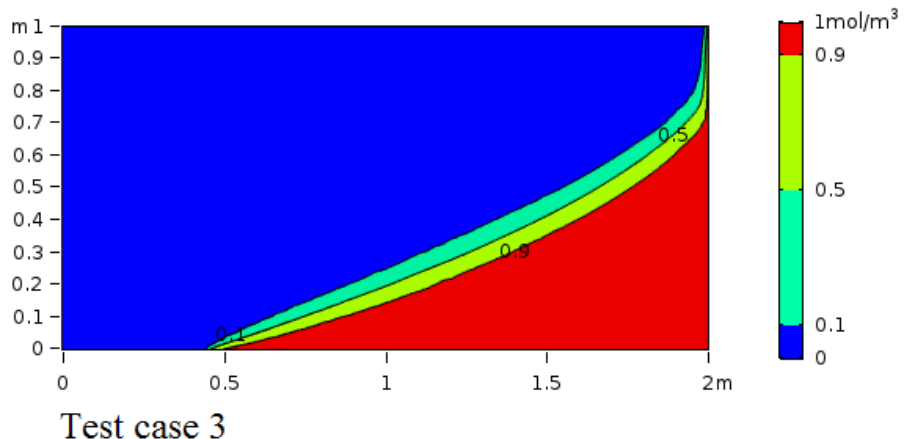

Figure 3. Comparison of COMSOL against the semi analytical solutions by Fahs et al. [2016]. Main isochlors (75\%, 50\% and $25 \%$ ) with COMSOL (Flood) and semianalytical (lines).

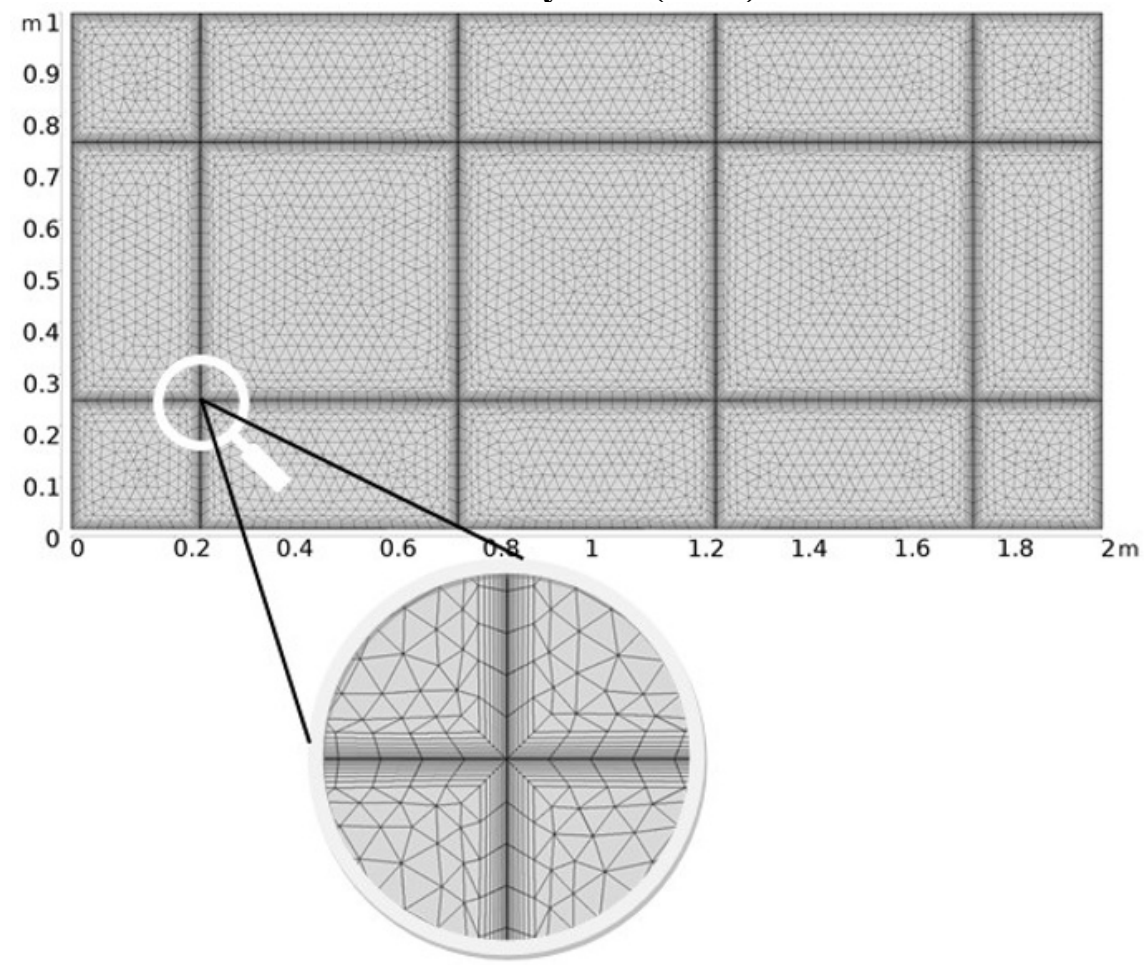

Figure 4. The boundary layer mesh used in COMSOL simulations. 


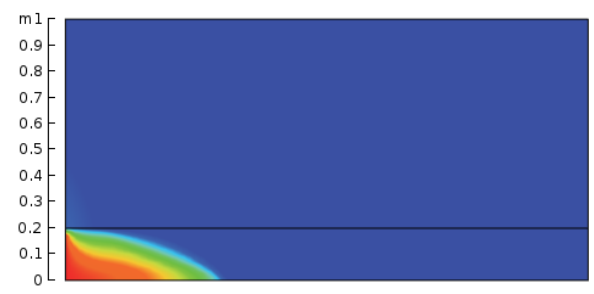

Case A

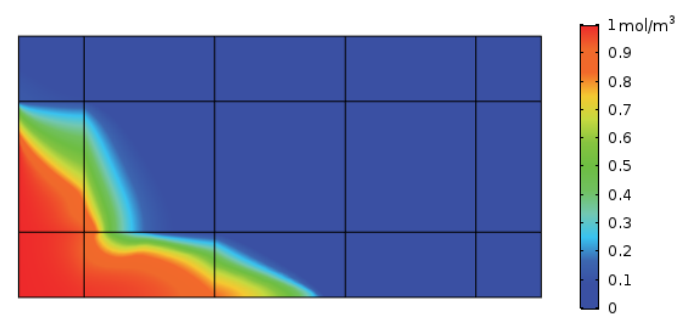

Case B

Figure 5. Concentration distribution obtained with COMSOL in the case of fractured porous media.

\section{CONCLUSIONS}

In this paper, Henry problem is used to explore the ability of COMSOL Multiphysics for simulating SWI in fractured coastal aquifers. COMSOL results are compared against semianalytical solutions, an in-house numerical code and existing results based on HydroGeosphere code. Results show that the DFN model allows accurate simulations of the SWI in coastal aquifer. The benchmark results show that the COMSOL software has the capability to simulate subsurface flow and it is a useful tool for the development of the conceptual models of SWI in fractured aquifers. The user interface in this software facilitates modelling process: defining geometry, mesh generation, PDE equations editing and coupling, solving, and post-processing. COMSOL is also flexible in including variable concentration boundary conditions at the seaside.

\section{REFERENCES}

Werner, A. D., M. Bakker, V. E. A. Post, A. Vandenbohede, C. Lu, B. Ataie-Ashtiani, C. T. Simmons, D. A. Barry, 2013. Seawater intrusion processes, investigation and management: Recent advances and future challenges. Advances in Water Resources 51, 3-26, doi:10.1016/j.advwatres.2012.03.004.

COMSOL Multiphysics, 2012. User's Guide, Version 4.3. Comsol Inc.

Sebben, M. L., A. D. Werner, and T. Graf. 2015. Seawater intrusion in fractured coastal aquifers: A preliminary numerical investigation using fractured Henry problem. Advances in water resources, 85, 93-108.

Ramasomanana, F., M. Fahs, H. M. Baalousha, N. Barth and S. Ahzi, 2018. An Efficient ELLAM Implementation for Modeling Solute Transport in Fractured Porous Media, Water Air Soil Pollut., 229:46, https://doi.org/10.1007/s11270-018-3690-8.

Fahs, M., B. Ataie-Ashtiani, A. Younes, C.T. Simmons, and P. Ackerer. 2016. The Henry problem: New semianalytical solution for velocity-dependent dispersion. Water Resources Research, 52, 7382-7407, doi:10.1002/2016WR019288.

Henry, H. 1964. Effects of dispersion on salt encroachment in coastal aquifer. U.S. Geol. Surv. Water Supply Pap., 1613, C70-C84.

Younes, A., M. Fahs, and S. Ahmed. 2009. Solving density driven flow problems with efficient spatial discretizations and higher-order time integration methods. Advances in Water Resources, 32, 340-352, doi:10.1016/j.advwatres.2008.11.003.

Contact Information: M. Fahs, Laboratoire d'hydrologie et de Géochimie de Strasbourg, 1 Rue Blessig, 67084, Strasbourg. Phone : 00333688504 48. Email : fahs@unistra.fr 